\title{
Evaluating a Health Education Web Site: The Case of AlcoholEdu
}

\author{
Andrew F. Wall
}

Building on the promise of interactive, multimedia education, this evaluation study examines an alcohol abuse prevention program, AlcoholEdu, delivered through an interactive Web-based format for the purpose of reducing the harm associated with student alcohol abuse. The study uses a clustered, randomly assigned post-test only evaluation design with 20,150 individuals to examine differences between individuals who have and have not yet received the educational program. Analyses examined the efficacy of the intervention among different groups of students: those who are members of Greek letter organizations, those referred because of judicial sanctions, or those entering their first year of study. Findings hint toward evidence that interactive health-related web tools can contribute to preventing high-risk student health behaviors in the campus environment, with self-reported evidence suggesting implementation among first-year students to be the most promising.

The Internet and other types and sources of technology-based information have become an integrated component of life for college students. Wireless Internet, podcasts, and online searches are commonplace in our digital world. Beyond the general scope and breadth of

Andrew F. Wall, Ph.D. is an assistant professor at the University of Rochester in the Margaret Warner School of Education and Human Development. 
technology as a mode of inquiry is evidence that health information Web sites are among those most visited (Baker, Wagner, Singer, \& Bundorf, 2003). The heavy use of health information Web sites is due both to ease of access and the discreet nature of discovery (Bensley $\&$ Lewis, 2002). An emerging area of health information on the Internet is the delivery of interactive Web sites that both present didactic information and interactive experiences for the purpose of enhancing health behavior change (Bensley et al., 2004; Wall, 2006). Interactive health information Web sites generally follow health behavior change theories. Many of these theories posit that messages can be tailored, or customized, to motivate behavior change (Ramos \& Perkins, 2006). The likelihood of behavior change is dependent on each person's level of desire and motivation to change personal behavior (Prochaska $\&$ DiClemente, 1984).

The development of a deep infrastructure of personal computers and telecommunications networks in the private sector and on college campuses allows complex interactive web-based programs to be developed and delivered to college students (Bensley et al., 2004). A series of efforts to deliver health education programs digitally via the Internet have taken advantage of this evolving capacity in the college environment (Wall, 2005a; Walters et al., 2005). These programs have targeted key student health issues such as alcohol abuse, smoking cessation, sexuality awareness, and depression. Among the most sophisticated products have been commercially developed Internetbased alcohol abuse prevention programs that report the capacity to deliver consistent health behavior change messages to thousands of college age students (Bersamin, Paschall, Fearnow-Kenney, \& Wyrick, 2007; Chiauzzi, Green, Lord, Thum, \& Goldstein, 2005; Wall, 2006). This article examines three questions related to an interactive webbased health education program that has been implemented broadly with college students for the purpose of mediating risky student behavior. Those questions include: (1) What is the theory of change that interactive Web sites follow in facilitating learning that is directed toward behavior change?, (2) What evidence is there that web-based health education can be implemented with broad reach among college students?, (3) What evidence is there that web-based health education can alter the behavior of those students who can be identified as atrisk for a particular health-related issue? 


\section{Program Description and Theory}

This report summarizes evidence on the short-term impact of a commercially available online health behavior change curriculum, AlcoholEdu for College ${ }^{\circledR}$ (AlcoholEdu) (OutsidetheClassroom, Inc., 2007). AlcoholEdu provides students with online interactive feedback about their health behaviors associated with alcohol. The interactive Web site strives to operationalize health behavior change theory by providing information about alcohol use and its consequences, developing student skills for functioning safely in a social environment, and providing students with opportunities to reflect on how the use of alcohol fits into an individual's life. The curriculum follows the success of a compact disk (CD) based program entitled "Alcohol 101" and is conceptually similar to several online health behavior change programs currently available including "MyStudentBody.com" and "CollegeAlc" (Bersamin et al., 2007; Chiauzzi et al., 2005; Michael, 2000; Paschall, Bersamin, FearnowKenney, Wyrick, \& Currey, 2006; Reis, Riley, \& Baer, 2000; Sharmer, 2001).

The description of the AlcoholEdu interactive Web site flows from interviews with program developers, a Web site review, and a review of AlcoholEdu documents. Based on those documents, descriptions, and reviews, a program theory, or logical connection of the Web site's learning activities and intended outcomes, was developed (see Figure 1).

Students are notified of the existence of the AlcoholEdu Web site through e-mail from an administrator on their campus. Using information in the e-mail, students progress through the AlcoholEdu Web site by opening their web browser, logging onto the program, and completing a pre-survey of their alcohol attitudes and behavior. Following the pre-survey, students complete a pre-course introduction, five online learning chapters, a journal, two knowledge tests and immediately upon course completion, a post-survey. An email follow-up is sent to students 4 to 6 weeks after completing their post-survey, asking them to complete a follow-up survey of their alcohol-related attitudes and behaviors.

The theory of change of AlcoholEdu is built on three domains, all of which are documented as predictive factors in the extensive literature 
on young adults and alcohol use (Agostinelli, Brown, \& Miller, 1995; Baer, Kivlahan, Blume, McKnight, \& Marlatt, 2001; D'Amico \& Fromme, 2000; Kivlahan, Marlatt, Fromme, Coppel, \& Williams, 1990; Marlatt et al., 1998; McNally \& Palfai, 2003; Peeler, Far, Miller, \& Brigham, 2000; Ramos \& Perkins, 2006; Wall, 2005b; Walters, Bennett, \& Miller, 2000). Chapters 1 and 3 address alcohol expectancies as related to peer influence, advertising, and behavioral and legal consequences of excessive use. Chapters 2 and 4 introduce students to concepts of blood alcohol concentration and the physiological parameters of alcohol use. The final chapter presents ideas of self-efficacy as related to safe and responsible drinking. The program theory articulates that the five chapters are experienced in a linear fashion through streaming video, static content information, interactive web pages including decision trees and brief feedback, and reflective journaling. Chapters are delivered using varied learning approaches that program developers describe as following the Bloom (1956) taxonomy of learning. Thus chapters begin with the rote memorization of facts and proceed with more complex stages of analysis and assessment, culminating in the evaluation phase that requires participants to analyze different approaches to handling social situations with alcohol.

Even with varied learning approaches, the program is linear in that participants progress sequentially from chapter one to five. Within this linear design there is customization of chapters by gender and drinking status of participants. Customization creates four unique paths through the program, including: (a) men who report consuming, (b) men who report abstaining, (c) women who report consuming, and (d) women who report abstaining from alcohol. Examples of customization include self-reported consumers of alcohol receiving a message of moderating their consumption, while an abstainer receives messages reinforcing their choice to refrain from alcohol use. Customization by gender includes comparison points in feedback associated with blood alcohol level whereby a female student would be compared to other females and a male to other males (Lewis $\&$ Neighbors, 2006). Program content concludes with a knowledge quiz, or test, to assure a minimum level of comprehension prior to students logging off their online experience. 
NASPA Journal, 2007, Vol. 44, no. 4

Figure 1

\section{AlcoholEdu Program Theory}

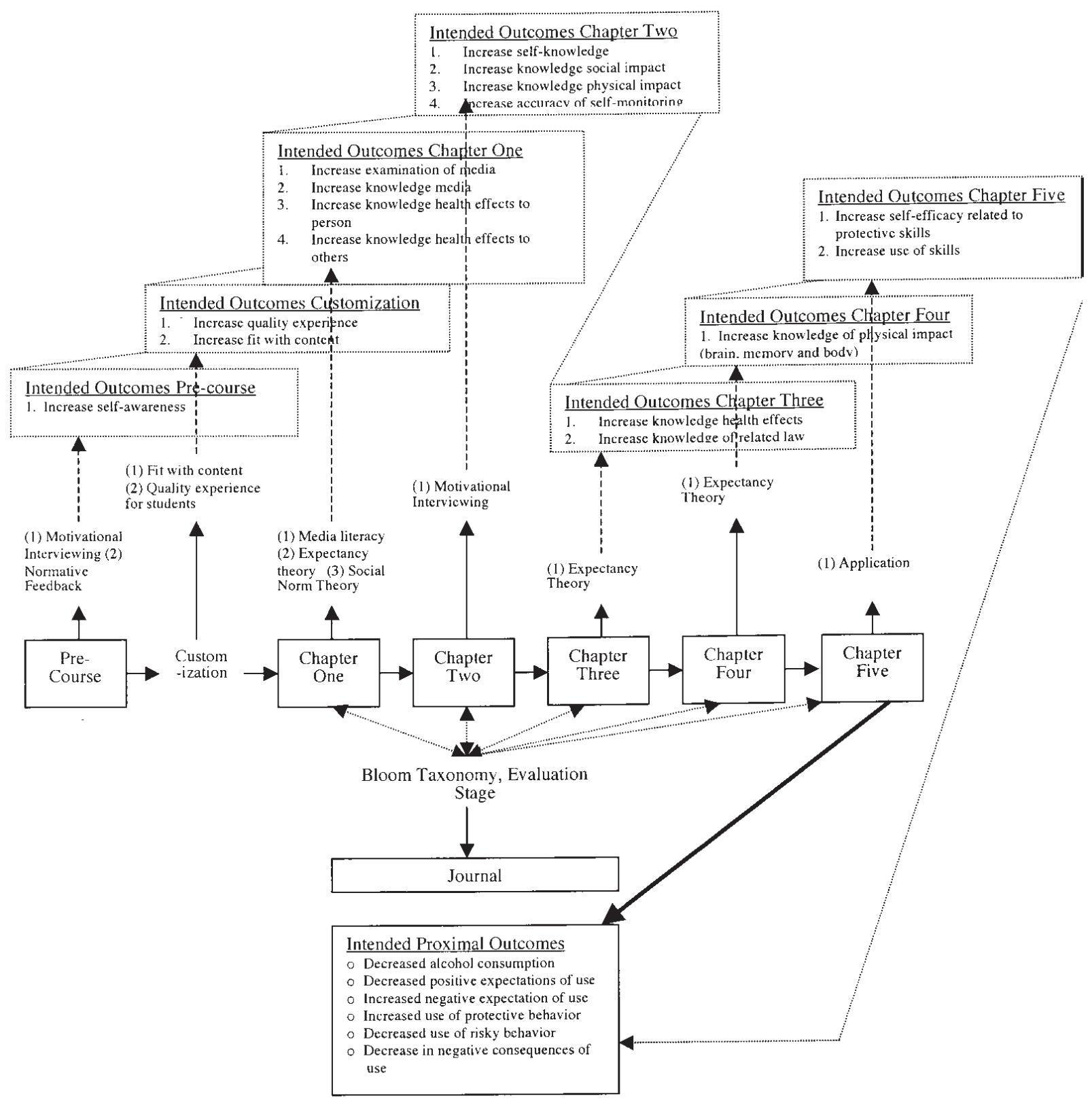




\section{Examining Interactive Web Health Tools with High-Risk Students}

The theory of behavior change of the AlcoholEdu interactive Web site draws upon the benefits of interactive technology to allow for broad program reach with messages that are tailored individually to the selfdescribed consumption and gender of each student. In the instance of alcohol use and abuse in the college context, a key concern for an interactive web tool is whether student groups who are often considered at-risk will experience changes in attitude and behavior associated with alcohol use and abuse. Among those at the greatest risk for harm associated with alcohol use are first-year students, members of Greek organizations, and those students involved in alcohol-related judicial infractions (Baer et al., 1995; Caldwell, 2002; Camlibel, 2000; Harford \& Muthen, 2001; Nelson \& Wechsler, 2001; Presley, Meilman, \& Leichliter, 2002; Tinto, 1993; Wechsler, Kuo, Lee, \& Dowdall, 2000).

Students who are members of Greek organizations have been shown to consume heavily more often than many of their college-attending peers (Caudill, Crosse, Campbell, Howard, Luckey, \& Blane, 2006). Greek organization members are at-risk of alcohol-related harm, but are also a visible and consequently reachable social grouping of students. Another population at risk of the harm associated with alcohol use is those students just beginning their college journey (Sher $\&$ Rutledge, 2007). First-year students in transition are undergoing a series of developmental challenges as they navigate college life rife with new social and developmental dynamics (Guiffrida, 2006; Sessa, 2005; White et al., 2006). Similar to Greek students and first-year students, students sanctioned for judicial infractions hold a special opportunity for alcohol intervention on a college campus (LaBrie, Lamb, Pedersen, \& Quinlan, 2006). The opportunity emerges in the one-on-one dialogue of a judicial setting and potential for programmatic follow-up.

The personal and interpersonal harm attributed to each of these atrisk groups has been well documented and ranges from creating annoying noise to interpersonal violence, property damage, diminished academic engagement, and occasionally alcohol-related fatalities (Hingson et al., 2002; Murphy, Hoyme, Colby, \& Borsari, 
2006; Perkins, 2002; Powell \& Wechsler, 2003). At-risk groups represent identified populations for prevention services, but campus health professionals working with these groups have a limited number of program and policy options with evidence of efficacy (Mitchell, Toomey, \& Erikson, 2005; Walters, Bennett, \& Noto, 2000). The most promising program options to date are one-to-one or small group interactions that have limited economy of scale (Hunter \& Mazurek, 2004; LaBrie, Pedersen, Lamb, \& Quinlan, 2007; McNally \& Palfai, 2003). Program formats such as individual brief screening and feedback have strong evidence of efficacy for heavy college drinkers, but are limited in their scale by resource intensity, including cost of staff to provide services (LaBrie et al., 2006; Lewis \& Neighbors, 2006). Efforts that have a greater economy of scale, such as social marketing and alcohol alternative events, have more mixed findings as to their impact; i.e. evaluation findings have not shown consistent evidence of alcohol-related behavior change (Perkins \& Craig, 2006; Thombs, Dotterer, Olds, Sharp, \& Raub, 2004; Wechsler et al., 2003).

In our era of the Internet, online interactive web tools hold special promise. Interactive technology as an out-of-class learning modality has economies of scale, provides consistent education messages, and presents tailored messages geared to the interests and information needs of a given user (Reis, Riley, Lokman, \& Baer, 2000; Wall \& Cox, 2001). Location of delivery is far more flexible than other types of presentations-i.e., anywhere a personal computer can be connected to the Internet.

\section{Methods}

Online web page surveys were completed during the 2003-04 academic year by college students at 225 institutions of higher education as part of the AlcoholEdu online alcohol education program. Program participants completed three attitude- and behavior-based surveys with timing of survey administration being: (a) a 36-question pre-survey, (b) an immediate post-survey, and (c) a 21-question follow-up survey done 4 to 6 weeks after completing the program. The analysis presented here is based on the subset of students who completed all program elements and all surveys. All student responses were anonymous. 
Students who were documented as starting the program but not having completed all program elements and surveys were most likely to have ceased their participation at three points. First, they may have taken the pre-survey, which documents them as starting the course, but not have progressed to actually go through course material $(\mathrm{N}=$ 50,300 pre-surveys completed). Second, individuals may have completed program material, but failed to pass the knowledge quiz and therefore do not complete the post-survey offered immediately after program completion ( $N=45,110$ post surveys completed or $89.6 \%$ of pre-survey completers). Third, individuals can complete program materials, successfully pass the knowledge quiz, but fail to complete the follow-up survey 4-6 weeks after program completion and thus were excluded from this study ( $N=24,877$ follow-up surveys completed or $49.5 \%$ of pre-survey completers).

A post-test only design was used for this evaluation study. The posttest design was created through retrospective analysis of data involving three steps. The first step was a clustered random assignment of responses to intervention and comparison groups. The second step was assignment of responses to time blocks to facilitate comparing the two study groups at similar time points. Finally, the study used presurvey responses from the comparison group and follow-up survey responses from the intervention group as data for the post-test only design framework.

Clustered group formation was based upon the 24,877 students' campus affiliations and program delivery formats. The delivery formats included pre-matriculation (7.3\%), a first-year orientation (11.3\%), first-year student requirement (32.7\%), educational credit (3.7\%), judicial/disciplinary referral (21.1\%), requirement for all students (in all classes [3.3\%]), athletic team (.5\%), fraternity or sorority (17.2\%), and other formats (mixed format, other counseling and residence life [2.9\%]). Combining delivery format with the 225 unique institutional affiliations created 617 clustered groups for random assignment. Each group reflected the learning environments in which students used AlcoholEdu.

In this analysis all surveys included a date stamp, denoting the day of the year that a particular survey was completed. The date stamp was used to group survey responses into 4 -week time intervals, so as to 
allow for analysis of survey responses of the comparison (those who have not yet completed the program) and the intervention (program completers) at similar time points in the academic year. There were thirteen time blocks dated from July 1, 2003 to June 20, 2004.

Five dependent variables were examined in the analysis. Two measures were derived from 20 items related to self-reported negative consequences that follow the stem question, "In the past 2 weeks, if you were drinking, did you ...?" The 20 items were conceptually grouped and then factor analysis was conducted as reported in Table 1. Scales were created in a summative format due to the dichotomous coding of original items. The scales from these questions in this analysis include negative academic consequences and hangover/mental impact. The scales had Cronbach alpha scores of .830 and .768.

Following the same procedure of conceptual grouping and then factor analysis, two additional scales were included as dependent variables. One scale was created from eight items related to the self-reported risk behavior stem question, "In the past 2 weeks, if you were drinking, did you ever ...?" Three items were combined into a risky behavior that is intentional scale. The final scale is related to attitudes toward alcohol use, and it comes from 10 items related to the stem question, "If I were drinking alcohol I would ...?" Eight items were combined to form a positive expectation of alcohol scale. The risky behavior that is intentional and positive expectation of alcohol scales had Cronbach Alpha scores of .756 and .906 respectively.

The fifth dependent measure, incidents of consuming 5 or more drinks in 1 day over the past 2 weeks, was created from self-reported drinks of individuals over the previous two weeks. The threshold of 5 or more drinks in 1 day has been described by previous research as binge drinking and shown to be a level of consumption that correlates with increased alcohol-related harm (Engs et al., 1994; Wechsler et al., 1994). Students were asked to indicate how many times in the past 14 days they had consumed 5 or more drinks in one sitting. A 2-week average was then computed from all days reported with this amount of consumption (each day with 5 plus drinks coded as 1 ).

The general pattern of individuals' background characteristics shows similarity between the intervention and comparison groups. 
Approximately the same number of men and women were included in the analysis and the majority (95\%) were under the age of 21 and Caucasian (84\%). Regarding living arrangements, the intervention group, differed from the comparison group in the percent living in residence halls ( $58 \%$ verses $48 \% p<.000$ ), percent living at home with family ( $6 \%$ versus $2 \%, p<.000$ ), and percent living in a fraternity or sorority ( $3 \%$ versus $13 \%, p<.000$ ). No other statistically significant associations were observed between group membership and background characteristics. Twenty-one percent lived in substancefree residence halls, and 5\% respectively lived in an off-campus apartment or house. Science was the most frequently cited major (20\%), followed by business (14\%) and the social sciences (11\%).

Table 1

Dependent Variable Factor Analysis

\begin{tabular}{|c|c|c|}
\hline Variables & $\begin{array}{l}\text { Factor } \\
\text { Loading }\end{array}$ & $\begin{array}{l}\text { Cronbach } \\
\text { Alpha }\end{array}$ \\
\hline Negative Academic Consequences & & .830 \\
\hline Miss a class? & .770 & \\
\hline Find yourself unfocused in class? & .804 & \\
\hline Attend a class unprepared? & .795 & \\
\hline Miss a deadline for a class? & .693 & \\
\hline Attend a class drunk? & .680 & \\
\hline Attend a class hung over? & .727 & \\
\hline Hangover/Mental Impact & & .768 \\
\hline Have a hangover? & .735 & \\
\hline Have to be prompted to remember something you did? & .842 & \\
\hline $\begin{array}{l}\text { Awaken from a night of drinking not able to remember things that } \\
\text { you did or places that you went? }\end{array}$ & .793 & \\
\hline Risky Behavior that is Intentional & & .756 \\
\hline $\begin{array}{l}\text { Choose a drink containing more alcohol and/or less mixer so that it } \\
\text { would affect you more quickly? }\end{array}$ & .661 & \\
\hline Start drinking before going out? & .852 & \\
\hline Play drinking games? & .837 & \\
\hline Positive Expectations of Alcohol & & .906 \\
\hline Feel less stressed & .759 & \\
\hline Find it easier to express my feelings & .813 & \\
\hline Feel more attractive & .775 & \\
\hline Feel less self-conscious about my body or my weight & .765 & \\
\hline Feel less comfortable in social situations & .786 & \\
\hline Have a better social life than if I were not drinking & .735 & \\
\hline Feel more connected with or close to the people around me & .799 & \\
\hline Feel less bored & .762 & \\
\hline
\end{tabular}


Table 2 provides a description of the trends associated with the five dependent measures in the study across time blocks: (a) negative academic consequences, (b) hangover/mental impact, (c) heavy consumption days, (d) risky behavior that is intentional, and (e) positive expectations of alcohol use. The trends reveal that when considering the mean responses within a 4 -week time block, the intervention group trends lower on the first four and higher (increased disagreement) related to positive expectations of alcohol. This indicates that students who completed the program (intervention group), as compared to those who have not yet completed the program (comparison group), self-report on average fewer incidents of negative academic consequences, hangover/mental impact, and risky behavior that is intentional and incidents of consuming 5 or more drinks in 1 day over the past 2 weeks. The intervention group also reported higher disagreement with positive expectations of alcohol use. Both groups report increased incidents of negative consequences and heavy consumption from the beginning of 2003 until well into 2004.

Independent, or predictor, variable inclusion was conceptually driven to address the delivery format, study group, survey administration timing, individual background characteristics, environmental variables, and self-reported abstainers of alcohol use. Examination of intervention and comparison groups was conducted through the study group variable (intervention group $=1$, comparison $=0$ ). The program delivery format variables were dichotomously coded to describe who received the program as part of an entire freshman class implementation, as part of a judicial referral, or as part of fraternity or sorority membership (yes $=1$, no $=0$ ). To control for timing of survey completion, given the observed overall increase in dependent variables for the academic year, 4-week time blocks are included as independent variables (yes $=1$, no $=0$ ). Analysis included time blocks 3 through 11 or all blocks in which the intervention and comparison group time block had at least 20 responses (see Table 2). Background independent variables related to alcohol use, behavior, and attitudes in analysis included gender $(1=$ female, $0=$ male $)$, age $(1=18$ to $7=$ 24 and above), grade point average ( $1=\mathrm{A}$ to $11=\mathrm{F})$, White or Caucasian $(1=$ yes, $0=$ no), and business major $(1=$ yes, $0=$ no $)$. Environmental variables included in analysis included living in fraternity or sorority house $(1=$ yes, $0=$ no), living at home $(1=$ yes, 
Table 2

Time Blocks and Incidents of Heavy Alcohol Consumption, Negative Consequence Scales, and Positive Expectations

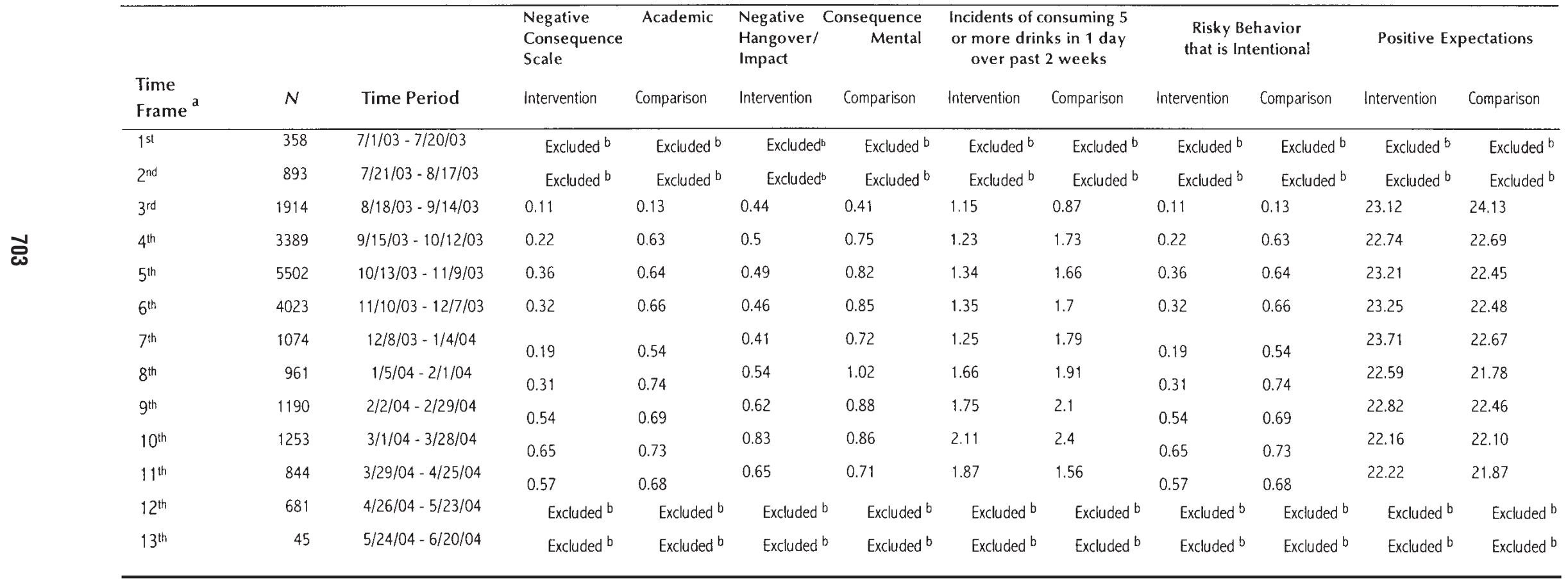

${ }^{\text {a }}$ Four-week time block.

${ }^{b}$ Excluded for less than 20 individual responses in either intervention or comparison cell in this time block. 
$0=$ no), and living in substance-free residence hall ( $1=$ yes, $0=$ no). The final independent variable in analysis denotes those individuals who self-report being abstainers of alcohol $(1=$ yes, $0=$ no $)$. Approximately $95 \%$ of those who report abstaining from alcohol also report consuming no alcohol in the past 2 weeks.

\section{Limitations}

There are a series of limitations associated with the methodology of this study. First, all data are self-reported and rely on accurate reports of individuals as to their alcohol attitudes, use, and related behavior. Individuals assigned to the intervention group who completed both a pre-survey (immediately prior to program) and post-survey (immediately after program) during program implementation prior to the follow-up survey are particularly prone to issues associated with self-reporting. Programmatic impact is not distinguished from the potential press for social acceptability, boredom, or other factors that may occur due to the completion of multiple similar surveys or from the social context of the intervention. Additionally, while study group participants are similar in their background characteristics, differences in background factors (particularly living situation) reported can provide a rival explanation for differences observed between groups on dependent variables.

\section{Results}

Linear regression models were developed for five dependent variables (see Table 3). Regression models were developed for each dependent variable. There were 20,150 student responses examined in regression analysis. Analyses show a negative association of the intervention to four dependent variables, indicating that the intervention group selfreported fewer negative academic consequences, hangover/mental impact, incidents of consuming 5 or more drinks in 1 day over the past 2 weeks, and incidents of intentional risky behavior when other variables in the model are controlled. The negative association of the study group variable was statistically significant for the dependent variables. Regression findings confirm descriptive analysis that students participating in the intervention group self-reported lower incidents of negative consequences, heavy alcohol use days, and 
incidents of intentional risky behavior than the comparison group of students who had not yet completed the curriculum at a similar time point in the 2003-04 academic year. The regression analysis shows a statistically significant positive association of the intervention group with the positive expectation of alcohol use variable, indicating an increased disagreement with positive expectations of alcohol use.

The study group variable is one of the two strongest independent variables for the five dependent variables when examining the standardized coefficients (absolute b's value in five models from .111 to .213). Of particular interest is the combination of the study group variables in each model. In each instance the study group variable's standardized coefficient is mediated by the three delivery format variables. The first-year full class implementation variable retains more of the study group association with the dependent variable than do either judicial referral or Greek chapter delivery format variables. As an example, results of the incidents of consuming 5 or more drinks a day over the past 2 weeks variable show an overall mean of 1.818, with the unstandardized coefficient predicting that the intervention group will have .575 lower incidence of heavy consumption days than the comparison when other variables are held constant. This finding is mediated by the delivery format. For individuals who received the program as a part of an entire first-year class implementation, the analysis predicts a .143 higher incidence of heavy consumption. The difference in incidence of heavy consumption for students experiencing the program through first-year class implementation is .432 lower than the comparison group. For students in the intervention group experiencing the curriculum as part of their Greek organization or as a judicial referral, there is greater mediation of .393 and .514 respectively of the study group variable. Analysis of delivery format variables indicates that the first-year class implementation variable moderates the study group variable less than the Greek or judicial implementation variables. This finding is consistent across the five dependent variables in the model.

Analysis of additional independent variables confirms and offers possibilities to extend the program theory of the web-based intervention. The program theory includes customization, or unique program paths, for men and women along with self-reported consumers and nonconsumers. The gender (absolute $\beta=.022$ to .055 ) 
NASPA Journal, 2007, Vol. 44, no. 4

Table 3

Regression Findings for Five Dependent Variables

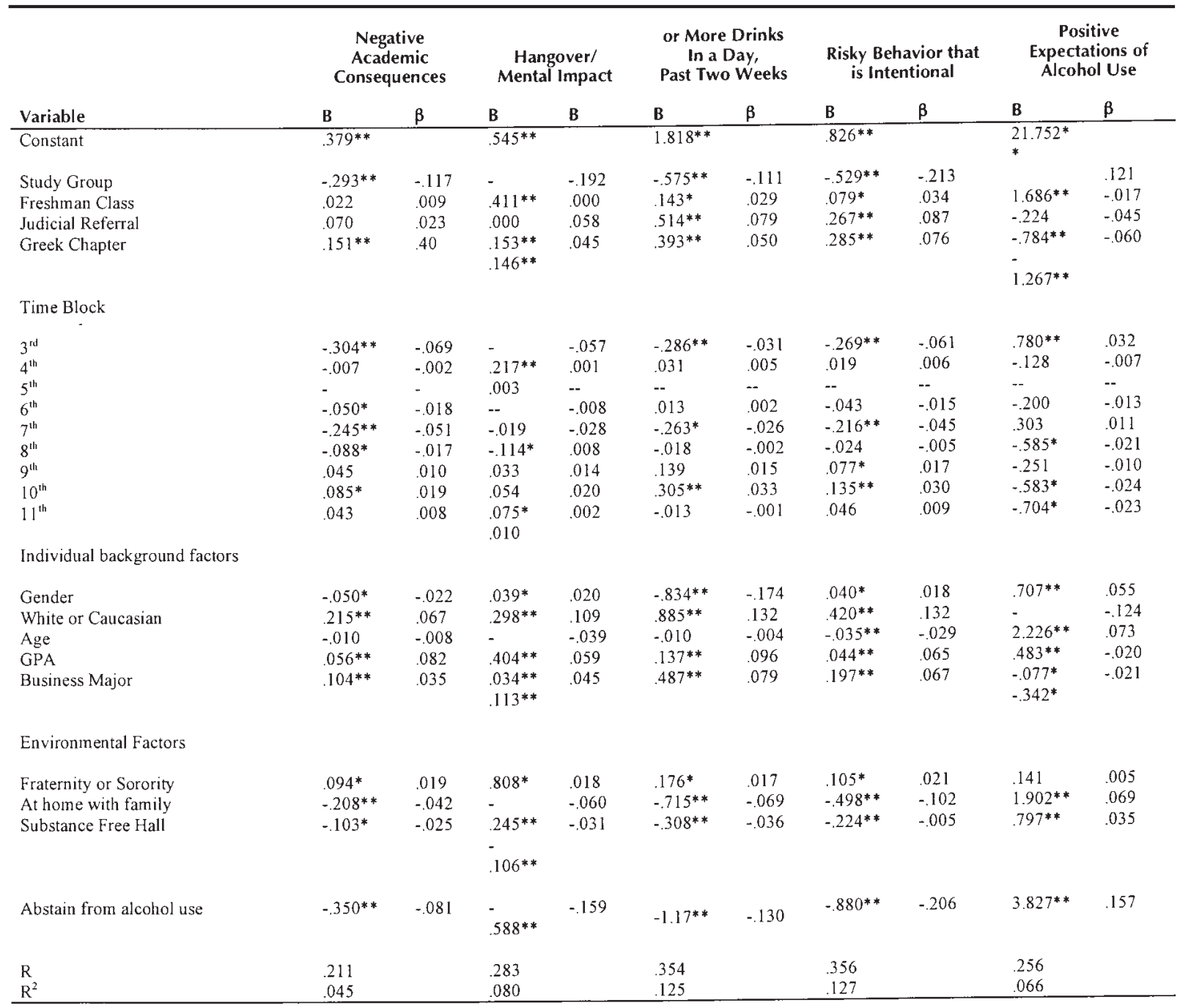

${ }^{*} p<.05 .{ }^{* *} p<.000$.

and consumer status (absolute $\beta=.081$ to .206) variables are both statistically significant predictors for each of the dependent variables, with the standardized coefficient for the abstainer variable being one of the two strongest in the model. Other statistically significant independent background variables in the model suggesting further consideration for program customization include race/ethnicity, academic performance level, and college major. Program customization to address unique individual differences associated with alcohol use, consequence, and attitudes offer specific guidance as to how the program might be further refined (see Table 3). Similarly, 
delivery format and environmental factors are significant independent variables in the five regression models. Environment and delivery format are data points to consider in a program theory that integrates the context of implementation, along with individual background characteristics.

A final element of the analysis of the regression models is the examination of overall model strength through variance predicted by the model. In all models, variance predicted in the dependent variable by the independent variables is limited $\left(R^{2}=.127\right.$ to .045$)$. Relatively stronger overall models are seen for incidents of heavy alcohol consumption and risky behavior that is intentional.

\section{Discussion}

Findings from this examination reveal that directed health information on the web has both significant reach and evidence of association with small degrees of self-reported attitude and behavior differences in relationship to a comparison group. Given descriptive process information showing that AlcoholEdu reached over 50,000 users initially, 45,000 who received the full content of the program and nearly 25,000 who completed a 4- to 6-week follow-up survey, the capacity of a web health education tool to reach a broad number of individuals appears promising.

In terms of likely attitude and behavior change from an online health behavior change tool, the evidence provided by this study is that the intervention group participants self-reported fewer negative consequences, incidents of heavy drinking, and risky behavior that is intentional than a comparison group as measured 4 to 6 weeks after program completion. Additionally, the intervention group expressed more disagreement with positive expectations of alcohol use than the comparison group. The differentials in negative events, drinking patterns, and risky behavior were maintained throughout much of the school year, even though across the 7 months covered in the study there was a steady increase in both incidents and amount of alcohol reported consumed for both groups. It is notable that the intervention effect is small, but held over time across institutions and for at-risk groups within a given college or university. 
The results speak first to the potential value of web-based health behavior change tools that are interactive and can be tailored to the interests and learning needs of specific at-risk student audiences. Second, differences in effect sizes noted between groups and delivery formats indicate in what delivery format the program is most likely to have maximum benefit. Third, the longitudinal pattern of drinking and outcomes raises a series of questions including the timing of such an intervention within the academic year, the role of booster experiences designed to maintain the initial intervention effect, and the audiences benefiting from additional intervention. These issues would be best addressed in a prospective study with random assignment to the program and a delayed control group. Such a study design would build on the cross-sectional data reported on here. Additionally a design might be instituted that controls for the possibility of salience effects—students' thinking they should provide socially acceptable responses.

For those groups of students identified to be at-risk in the college environment, this analysis builds on two existing studies that indicate web-based health behavior change tools have potential to shift attitudes and behavior associated with alcohol use (Bersamin et al., 2007; Chiauzzi et al., 2005; Paschall et al., 2006). Among high-risk student populations, the consistent trend among students in the intervention group of fewer negative consequences, fewer days of heavy consumption, a lower prevalence of intentional risky behavior, and increased disagreement with positive expectation of alcohol use is a promising indicator of the way the program functions across the campus social milieu. The differences found in effect sizes related to at-risk group implementation suggest that the extent to which a program has impact is likely influenced by the conditions under which an individual experiences the intervention.

The strongest effect sizes emerge from implementation with students from an entire campus first-year class. This finding is not surprising in relationship to Greek organization members or judicial referrals, in that the first-year student is new to the collegiate experience and just beginning to integrate social expectations into their understanding of college life. The ability of web tools to deliver with integrity consistent but customized messages to students represents an opportunity for creating a common dialogue upon which first-year student social and 
drinking expectations can be based. The question of understanding how universal education among first-year students operates demands further examination.

The psychological disposition that Greek organization members and judicial referrals bring to their program experience is likely a component of how they interpret and synthesize messages associated with alcohol use. For Greek organization members who have been bombarded with news that they are at-risk and are likely to be heavy consumers of alcohol, any alcohol prevention effort must be clouded with some sense of "here we go again." An anticipated skepticism of prevention efforts, coupled with strong organizational cultures, means that the small but significant findings are promising results; stronger effect sizes among this group may be both suspect and unrealistic for a brief intervention.

The small effect sizes found for those individuals who are mandated as a result of disciplinary action to participate in an alcohol education course point to the challenge of working with this population. The analysis of judicially referred program participants lends support that in spite of the likely disposition of these students toward their experience, an online educational experience can positively influence attitudes and behaviors, albeit in small ways. While it is encouraging that the trends seen in the other analyses persist among this group, larger effect sizes have been observed using small group motivational interventions (LaBrie et al., 2006).

There is potential for interactive web applications to provide education messages that are both scalable and have interactive features that allow for individual educational experiences. However, the limited findings suggest that AlcoholEdu, and like web-based alcohol education programs, are best adopted in the context of multifaceted alcohol education efforts. These efforts should incorporate education, policy, and enforcement that work to alter individual behavior and the college culture associated with alcohol use. Web-based tools, while offering new opportunities for reaching students with important alcohol related information, are most appropriately seen as one of many tools in the effort to ameliorate the harm associated with heavy student alcohol use. 
While the vision of web-based health education has yet to be fully realized, this evaluation report summarizes the small, but promising, results of one curriculum that has been delivered to groups of highrisk college students. The evidence herein supports the continued efforts of health educators in college settings to apply evolving technology as a tool in addressing short-term harm associated with heavy alcohol use among the most challenging student populations.

\section{References}

Agostinelli, G., Brown, J. M., \& Miller, W.R. (1995). Effects of normative feedback on consumption among heavy drinking college students. Journal of Drug Education, 25(1), 31-40.

Baer, J. S., Kivlahan, D. R., \& Marlatt, G. A. (1995). High-risk drinking across the transition from high school to college. Alcoholism: Clinical \& Experimental Research, 19(1), 54-61.

Baer, J. S., Kivlahan, D. R., Blume, A.W., McKnight, P., \& Marlatt, B. A. (2001). Brief intervention for heavy-drinking college students: 4-year follow-up and natural history. American Journal of Public Health, 91(8), 1310-1316.

Baker, L., Wagner, T.H., Singer, S. \& Bundorf, K. (2003). Use of the Internet and e-mail for health care information: Results from a national survey. JAMA, 289, 2400-2406.

Bensley, R. J., \& Lewis, J. (2002). Analysis of Internet-based health assessments. Health Promotion and Practice, 3(4), 463-476.

Bensley, R. J., et al. (2004). The eHealth behavior management model: A stage-based approach to behavior change and management. Preventing Chronic Disease, 1(4), Al4.

Bersamin, M., Paschall, M.J., Fearnow-Kenney, M., \& Wyrick, D. (2007). Effectiveness of a web-based alcohol-misuse and harmprevention course among high-and low-risk students. Journal of American College Health, 55(4), 247-254.

Bloom, B. S. (1956). Taxonomy of educational objectives, handbook I: The cognitive domain. New York: David McKay Co.

Caldwell, P.E. (2002). Drinking levels, related problems and readiness to change in a college sample. Alcoholism Treatment Quarterly, 20(2), 1-15.

Camlibel, A. R. (2000). Affectivity and attachment: A comparison of binge drinking and non-binge drinking first-year college students. Dissertation Abstracts International, 60(11), 5757. 
Caudill, B. D., Crosse, S. B., Campbell, B., Howard, J., Luckey, B., \& Blane, H. T. (2006). High-risk drinking among college fraternity members: A national perspective. Journal of American College Health, 55(3), 141-155.

Chiauzzi, E., Green, T. C., Lord, S., Thum, C., \& Goldstein, M. (2005). My Student Body: A high-risk drinking prevention Web site for college students. Journal of American College Health, 53(6), 263-274.

D'Amico, E. J., \& Fromme, K. (2000). Implementation of the risk skills training program: A brief intervention targeting adolescents participating in risk behaviors. Cognitive Behavior \& Practice, 7 , 101-117.

Engs, R. C., Diebold, B. A., \& Hanson, D. J. (1994). The drinking patterns and problems of a national sample of college students. Journal Alcohol Drug Education, 41, 13-33.

Ferrell, E. F. (2002, November 11). Moist, Not Dry. The Chronicle of Higher Education. Accessed On Line at www.chronicle.com July 28, 2005.

Guiffrida, D. A. (2006). Toward a cultural advancement of Tinto's theory. The Review of Higher Education, 29(4), 451-472.

Harford, T. C., \& Muthen, B. O. (2001). Alcohol use among college students: The effects of prior problem behaviors and change of residence. Journal of Studies on Alcohol, 62(3), 306-312.

Hingson, R. W., Heeren, T., Zakocs, R. C., Kopstein, A., \& Wechsler, H. (2002). Magnitude of alcohol-related mortality and morbidity among U. S. college students ages 18-24. Journal of Studies on Alcohol, 63(2), 136-145.

Hunter, F. J., \& Mazurek, M. B. (2004). The effectiveness of intervention studies to decrease alcohol use in college undergraduate students: An integrative analysis. Worldviews on Evidence-based Nursing, 1(2), 102-119.

Kivlahan, D. R., Marlatt, G. A., Fromme, K., Coppel, D. B., \& Williams, E. (1990). Secondary prevention with college drinkers: Evaluation of an alcohol skills training program, Journal of Consulting and Clinical Psychology, 58(6), 805-810.

LaBrie, J. W., Lamb, T. F., Pedersen, E. R. \& Quinlan, T. (2006). A group motivational interviewing intervention reduces drinking and alcohol-related consequences in adjudicated college students. Journal of College Student Development, 47(3), 267-280. 
LaBrie, J. W., Pedersen, E. R., Lamb, T. F. \& Quinlan, T. (2007). A campus-based motivational enhancement group intervention reduces problematic drinking in freshman male college students. Addictive Behaviors, 32(5), 889-901.

Lewis, M. A., \& Neighbors, C. (2006). Optimizing personalized normative feedback: The use of gender-specific referents. Journal of Studies on Alcohol and Drugs, 68(2), 228-237.

Marlatt, G. A., et al. (1998). Screening and brief intervention for highrisk college student drinkers: Results from a 2-year follow-up assessment. Journal of Consulting \& Clinical Psychology, 66(4), 604-615.

McNally, A. M., \& Palfai, T. P. (2003). Brief group alcohol interventions with college students: Examining motivational components. Journal of Drug Education, 33(2), 159-176.

Michael, M. E. (2000). Attitudes and perceived behavioral control of first-year college student's alcohol use: A study of an instructional software intervention. Dissertation Abstracts International, 61(5), 2495.

Mitchell, R. J., Toomey, T. L., \& Erikson, D. (2005). Alcohol policies on college campuses. Journal of American College Health, 53(4), 149-157.

Murphy, J. G., Hoyme, C. K., Colby, S. M., \& Borsari, B. (2006). Alcohol consumption, alcohol-related problems, and quality of life among college students. Journal of College Student Development, $47(1), 110-121$.

Nelson, T. F., \& Wechsler, H. (2001). Alcohol and college athletes. Medicine \& Science in Sports \& Exercise, 33(1), 43-47.

Outside the Classroom, Inc. (2007, January 5). Accessed on-line on January 5, 2007 at www.outsidetheclassroom.com.

Paschall, M. J., Bersamin, M., Fearnow-Kenney, M., Wyrick, D., \& Currey, D. (2006). Short-term evaluation of a web-based college alcohol misuse and harm prevention course (College Alc). Journal of Alcohol and Drug Education, 50(3), 49-65.

Peeler, C. M., Far, J., Miller, J., \& Brigham, T. A. (2000). An analysis of the effects of a program to reduce heavy drinking among college students. Journal of Alcohol and Drug Education, 45(2), 39-54.

Perkins, H. W. (2002). Surveying the damage: A review of research on consequences of alcohol misuse in college populations. Journal of Studies on Alcohol, 63(2), 91-100. 
Perkins, H. W., \& Craig, D. W. (2006). A successful social norms campaign to reduce alcohol misuse among college studentathletes. Journal of Studies on Alcohol, 67(6), 880-889.

Powell, W. J., \& Wechsler, H. (2003). Does alcohol consumption reduce human capital accumulations? Evidence from the college alcohol study. Applied Economics, 25(10), 1227-1239.

Presley, C. A., Meilman, P. W., \& Leichliter, J. S. (2002). College factors that influence drinking. Journal of Studies on Alcohol, 63(2), 82-90.

Prochaska, J. O., \& DiClemente, C. C. (1984). The transtheoretical approach: Crossing the traditional boundaries of therapy. Melbourne, Florida: Krieger Publishing.

Ramos, D., \& Perkins, D. F. (2006). Goodness of fit assessment of an alcohol intervention: Program and underlying theories of change. Journal of American College Health, 55(1), 57-64.

Reis, J., Riley, W., \& Baer, J. (2000). Interactive multimedia preventive alcohol education: An evaluation of effectiveness with college students. Journal of Educational Computing Research, 23(1), 41-65.

Reis, J., Riley, W., Lokman, L., \& Baer, J. (2000). Interactive multimedia preventive alcohol education: A technology application in higher education. Journal of Drug Education, 30(4), 399-421.

Sessa, F. M. (2005). The influence of perceived parenting on substance use during the transition to college: A comparison of male residential and commuter students. Journal of College Student Development, 46(1), 62-74.

Sharmer, L. (2001). Evaluation of alcohol education programs on attitude, knowledge, and self-reported behavior of college students. Evaluation \& the Health Professions, 24(3), 336-357.

Sher, K. J., \& Rutledge, P. C. (2007). Heavy drinking across the transition to college: Predicting first-semester heavy drinking from precollege variables. Addictive Behaviors, 32, 819-835.

Tinto, V. (1993). Leaving college: Rethinking the causes and cures of student attrition (2nd ed.). Chicago: University of Chicago Press.

Thombs, D. L., Dotterer, S., Olds, R. S., Sharp, K. E., \& Raub, C. G. (2004). A close look at why one social norms campaign did not reduce student drinking. Journal of American College Health, 53(2), 61-68.

Wall, A. (2005a). Technology as a tool in alcohol attitude and behavior change. NASPA Leadership Exchange, Winter, 26-27. 
Wall, A. (2005b). On line health education curriculum evaluation: Differential findings among college students. Unpublished Dissertation. University of Illinois Urbana-Champaign.

Wall, A. (2006). On-line alcohol health education curriculum evaluation: Harm reduction findings among fraternity and sorority members. Oracle: The Research Journal of the Association of Fraternity Advisors, 2(1), 29-45.

Wall, A., \& Cox, E. (2000). Technology in housing alcohol education. ACUHO-I Journal, 29(1), 11-14.

Walters, S. T., Miller, E., \& Chiauzzi, E. (2005). Wired for wellness: e-interventions for addressing college drinking. Journal of Substance Abuse Treatment, 29(2), 139-45.

Walters, S. T., Bennett, M. E., \& Miller, J. H. (2000). Reducing alcohol use in college students: A controlled trial of two brief interventions. Journal of Drug Education, 30(3), 361-372.

Walters, S. T., Bennett, M. E., \& Noto, J. V. (2000). Drinking on campus: What do we know about reducing alcohol use among college students? Journal of Substance Abuse Treatment, 19(3), 223-228.

Wechsler, H., Davenport, A., Dowdall, G., Moeykens, B. \& Castillo, S. (1994). Health and behavioral consequences of binge drinking in college: A national survey of students at 140 campuses. Journal of the American Medical Association, 272(21), 1672-1677.

Wechsler, H., Kuo, M., Lee, H., \& Dowdall, G. W. (2000). Environmental correlates of underage alcohol use and related problems of college students. American Journal of Preventive Medicine, 19(1), 24-29.

Wechsler, H., Molnar, B. E., Davenport, A. E., \& Baer, J. S. (1999). College alcohol use: A full or empty glass? Journal of American College Health, 47(6), 247-252.

Wechsler, H., Nelson, T. E., Lee, J. E., Seibring, M., Lewis, C., \& Keeling, R. P. (2003). Perception and reality: A national evaluation of social norms marketing interventions to reduce college students' heavy alcohol use. Journal of Studies on Alcohol, 64(4), 484-494.

White, H. R., McMorris, B. J., Catalono, R. F., Fleming, C. B., Haggerty, K. P., \& Abbott, R. D. (2006). Increases in alcohol and marijuana use during the transition out of high school into emerging adulthood: The effects of leaving home, going to college, and high school protective factors. Journal of Studies on Alcohol, 67(6), 810-822. 